\title{
Selective Gas-Phase Conversion of Glycerol to Acetol Over Promoted Zirconia Solid Acid Catalysts
}

\author{
Gangadhara Raju, Padigapati S. Reddy and Benjaram M. Reddy ${ }^{*}$ \\ Inorganic and Physical Chemistry Division, Indian Institute of Chemical Technology, Uppal Road, Hyderabad - 500 \\ 607, India
}

\begin{abstract}
The vapour phase selective conversion of glycerol to acetol at normal atmospheric pressure in a fixed-bed micro reactor was investigated over $\mathrm{SO}_{4}{ }^{2-}$ and $\mathrm{WO}_{\mathrm{x}}$ promoted $\mathrm{ZrO}_{2}$ and $\mathrm{M}-\mathrm{ZrO}_{2}\left(\mathrm{M}=\mathrm{Al}_{2} \mathrm{O}_{3}\right.$ or $\left.\mathrm{TiO}_{2}\right)$ solid acid catalysts. The investigated sulfate and tungstate ion promoted zirconia-based catalysts were prepared by both coprecipitation and impregnation methods and calcined at $923 \mathrm{~K}$. The synthesized catalysts were characterized by means of X-ray powder diffraction, X-ray photoelectron spectroscopy, BET surface area and ammonia temperature-programmed desorption methods. Characterization results suggest that $\mathrm{SO}_{4}{ }^{2-}$ promoter strongly influences the physicochemical properties of the support oxides than $\mathrm{WO}_{\mathrm{x}}$. However, the $\mathrm{WO}_{\mathrm{x}}$ promoted catalysts exhibited better catalytic activity than $\mathrm{SO}_{4}{ }^{2-}$ promoted catalysts. Among various catalysts investigated, the $\mathrm{WO}_{\mathrm{x}} / \mathrm{Al}_{2} \mathrm{O}_{3}-\mathrm{ZrO}_{2}$ catalyst exhibited stable catalytic activity with the highest glycerol conversion of $99 \%$ and acetol selectivity of $74 \%$.
\end{abstract}

Keywords: Glycerol, acetol, acrolein, promoted zirconia.

\section{INTRODUCTION}

Presently, petroleum is the foremost energy source in the world, but its shortage has led to renewed interest in alternative sources of chemical feedstock and fuel. Biomass is a renewable and clean energy source, and its derived fuels are attractive alternatives to the fossil fuels, as well as source for variety of chemical intermediates [1]. Biomass also has conventional applications in industrial area, primarily for production of biodiesel. In the biodiesel production glycerol is the principal byproduct; around $10 \mathrm{Kg}$ of glycerol is created for every $100 \mathrm{Kg}$ of produced biodiesel. Furthermore, with the growth of the biodiesel industry, there is more glycerol than that current market can easily absorb. Besides, glycerol has a multitude of uses in the food, pharmaceutical and chemical industries, among others [2]. Therefore, the effective utilization of glycerol enlarges the economy of the whole biodiesel production process, and the conversion of glycerol to value added chemicals could be in agreement with the perception of green chemistry in terms of exploitation of renewable resources [3-6]. Moreover, glycerol is a biodegradable, recyclable and non-toxic liquid, highly stable under typical storage conditions and amenable to many chemicals $[7,8]$. In this manner, glycerol from renewable resources is considered to be an attractive and highly functionalized molecule for sustainable upcoming production of value-added chemicals like propanediols, acrolein, polyglycerol and so on, which are employed in the production of variety of compounds such as polymers, cosmetics, plastics and detergents [9-14].

\footnotetext{
*Address correspondence to this author at the Inorganic and Physical Chemistry Division, Indian Institute of Chemical Technology, Uppal Road, Hyderabad - 500 607, India; Tel: +91-40-27191714; Fax: +91-40-27160921; E-mails: bmreddy@iict.res.in; mreddyb@yahoo.com
}

The selective gas-phase conversion of glycerol to acetol has received adequate attention. Acetol could be used in a wide range of applications, including as a raw material for cigarette filters, in packaging, plastics, agriculture, pharmaceutical products and consumer goods. On the other hand, 1,2-propanediol is produced by hydrogenation of acetol [15]. However, there are only few studies on the conversion of glycerol to acetol [16-18]. Chiu et al. reported gas-phase conversion of glycerol to acetol in a semi-batch reactor at high pressures and temperature by reactive distillation method $[16,18]$. Therefore, there is tremendous interest to selectively convert glycerol to acetol under mild and most economical conditions. The present investigation was undertaken taking into account the aforesaid background, evaluating $\mathrm{SO}_{4}{ }^{2-}$ and $\mathrm{WOx}$ promoted $\mathrm{ZrO}_{2}$ and $\mathrm{M}-\mathrm{ZrO}_{2}\left(\mathrm{M}=\mathrm{Al}_{2} \mathrm{O}_{3}\right.$ or $\left.\mathrm{TiO}_{2}\right)$ solid acid catalysts for the gasphase conversion of glycerol to acetol at normal atmospheric pressure.

\section{MATERIALS AND METHODOLOGY}

\section{Catalyst Preparation}

$\mathrm{ZrO}_{2}$ was obtained by coprecipitation technique in accordance to the described method elsewhere [19]. The $\mathrm{ZrOCl}_{2}$ aqueous solution was dropped into a flask with constant stirring and the $\mathrm{pH}$ value was maintained at about 8 with dilute $\mathrm{NH}_{4} \mathrm{OH}$. The obtained precipitate was carefully washed with distilled water until free from chloride ions and dried at $393 \mathrm{~K}$ for $48 \mathrm{~h}$. The $\mathrm{M}-\mathrm{ZrO}_{2}\left(\mathrm{M}=\mathrm{Al}_{2} \mathrm{O}_{3}\right.$ or $\left.\mathrm{TiO}_{2}\right)$ mixed oxide (1:1 mole ratio based on oxides) was prepared by coprecipitation method. For the preparation of $\mathrm{Al}_{2} \mathrm{O}_{3}$ $\mathrm{ZrO}_{2}$, an aqueous solution containing the requisite quantities of $\mathrm{Zr}\left(\mathrm{NO}_{3}\right)_{4} \cdot x \mathrm{H}_{2} \mathrm{O}$ and $\mathrm{Al}\left(\mathrm{NO}_{3}\right)_{3} \cdot x \mathrm{H}_{2} \mathrm{O}$ were prepared separately and mixed together $(\mathrm{pH} 2)$. This solution was hydrolyzed with dilute ammonium hydroxide with vigorous stirring until the $\mathrm{pH}$ of the solution reached to 8-9. At this $\mathrm{pH}$, a white precipitate was formed and the precipitate was 
allowed to settle for 2 days. The resulting precipitate was filtered off and washed several times with deionized water and dried at $393 \mathrm{~K}$ for $12 \mathrm{~h}$. For the preparation of $\mathrm{TiO}_{2}$ $\mathrm{ZrO}_{2}$, an aqueous solution containing the requisite quantities of $\mathrm{TiCl}_{4}, \mathrm{ZrOCl}_{2}$, and urea were heated together to $368 \mathrm{~K}$ with vigorous stirring. In about $6 \mathrm{~h}$ of heating, as decomposition of urea progressed to a certain extent, the $\mathrm{pH}$ of the solution increased from 2 to more than 7 and the formation of precipitate gradually occurred. The precipitate was heated for $6 \mathrm{~h}$ more to facilitate aging. The resulting precipitate was filtered off, washed several times with deionized water until free from chloride ions, and dried at $393 \mathrm{~K}$ for $12 \mathrm{~h}$. A portion of the oven-dried material was calcined at $1073 \mathrm{~K}$ for $5 \mathrm{~h}$ in air atmosphere and stored in dry nitrogen atmosphere. The $\mathrm{WO}_{\mathrm{x}} / \mathrm{ZrO}_{2}$ catalyst was prepared by a wet impregnation method. To impregnate tungsten-oxide promoter (15 wt.\%), the desired quantity of ammonium metatungstate was dissolved in excess water separately and to which the powdered $\mathrm{Zr}(\mathrm{OH})_{4}$ was added. The $\mathrm{WO}_{\mathrm{x}} / \mathrm{M}-\mathrm{ZrO}_{2}\left(\mathrm{M}=\mathrm{Al}_{2} \mathrm{O}_{3}\right.$ or $\left.\mathrm{TiO}_{2}\right)$ catalyst containing 15 wt. $\% \mathrm{WO}_{\mathrm{x}}$ was prepared by a suspension impregnation method. To incorporate tungsten oxide, the requisite quantities of ammonium metatungstate was dissolved in excess water and the finely powdered oven-dried anhydrous $\mathrm{M}-\mathrm{ZrO}_{2}$ support was added to this solution and refluxed at $383 \mathrm{~K}$ for $2 \mathrm{~h}$. To prepare $\mathrm{SO}_{4}{ }^{2-} / \mathrm{ZrO}_{2}$, a $0.5 \mathrm{M}$ sulfuric acid solution $(30 \mathrm{ml})$ was poured into the finely powdered $\mathrm{Zr}(\mathrm{OH})_{4}$. To prepare $\mathrm{SO}_{4}{ }^{2-} / \mathrm{M}-\mathrm{ZrO}_{2}\left(\mathrm{M}=\mathrm{Al}_{2} \mathrm{O}_{3}\right.$ or $\left.\mathrm{TiO}_{2}\right)$, the oven-dried anhydrous $\mathrm{M}-\mathrm{ZrO}_{2}$ was immersed in $1 \mathrm{M} \mathrm{H}_{2} \mathrm{SO}_{4}$ solution $(30 \mathrm{ml})$ for $30 \mathrm{~min}$ to incorporate sulfate ions. The excess water was evaporated on a water bath. The resulting samples were oven-dried at $383 \mathrm{~K}$ for $12 \mathrm{~h}$ and calcined at $923 \mathrm{~K}$ for $5 \mathrm{~h}$ in air atmosphere [19-21]. The investigated $\mathrm{WO}_{\mathrm{x}} / \mathrm{ZrO}_{2}, \mathrm{WO}_{\mathrm{x}} / \mathrm{TiO}_{2}-\mathrm{ZrO}_{2}, \mathrm{WO}_{\mathrm{x}} / \mathrm{Al}_{2} \mathrm{O}_{3}-\mathrm{ZrO}_{2}, \mathrm{SO}_{4}{ }^{2-} / \mathrm{ZrO}_{2}$, $\mathrm{SO}_{4}{ }^{2-} / \mathrm{TiO}_{2}-\mathrm{ZrO}_{2}$ and $\mathrm{SO}_{4}{ }^{2-} / \mathrm{Al}_{2} \mathrm{O}_{3}-\mathrm{ZrO}_{2}$ catalysts are referred as WZ, WTZ, WAZ, SZ, STZ and SAZ, respectively.

\section{Catalyst Characterization}

X-ray powder diffraction patterns have been recorded on a Siemens D-5000 instrument by using a $\mathrm{Cu} \mathrm{K \alpha}$ radiation source and a scintillation counter detector. The specific surface areas of the catalysts were determined on a Micromeritics Gemini 2360 instrument by $\mathrm{N}_{2}$ physisorption at liquid nitrogen temperature. Before measurements, all the catalysts were dried in situ at $473 \mathrm{~K}$ for $2 \mathrm{~h}$ under vacuum. The temperature-programmed desorption (TPD) measurements were performed on an AutoChem 2910 instrument (Micromeritics, USA). A thermal conductivity detector was used for continuous monitoring of the desorbed ammonia and the areas under the peaks were integrated. Prior to TPD measurements, catalysts were pretreated at $473 \mathrm{~K}$ for $1 \mathrm{~h}$ in a

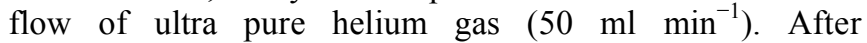
pretreatment, the sample was saturated with $10 \%$ ultra pure anhydrous ammonia gas (balance $\mathrm{He}, 75 \mathrm{ml} \mathrm{min}^{-1}$ ) at $353 \mathrm{~K}$ for $2 \mathrm{~h}$ and subsequently flushed with $\mathrm{He}\left(60 \mathrm{ml} \mathrm{min}^{-1}\right)$ at $383 \mathrm{~K}$ for $1 \mathrm{~h}$ to remove the physisorbed ammonia. The heating rate for the TPD measurements, from 383 to $1073 \mathrm{~K}$, was $10 \mathrm{~K} \mathrm{~min}^{-1}$. The XPS measurements were made on a Shimadzu (ESCA 3400) spectrometer by using $\mathrm{Mg} \mathrm{K \alpha}$ $(1253.6 \mathrm{eV})$ radiation as the excitation source. Charging of the catalyst samples was corrected by setting the binding energy of the adventitious carbon ( $\mathrm{C} \mathrm{1s}$ ) at $284.6 \mathrm{eV}$. The XPS analysis was done at room temperature and at pressures typically in the order of less than $10^{-6} \mathrm{~Pa}$. Catalysts were outgassed in a vacuum oven overnight before XPS measurements.

\section{Activity Measurements}

The gas-phase conversion of glycerol to acetol was conducted at $588 \mathrm{~K}$ under normal atmospheric pressure in a down-flow fixed-bed glass reactor ( $9 \mathrm{~mm}$ i.d.) using $0.5 \mathrm{~g}$ of catalyst. Before the reaction, the catalyst was pretreated at $673 \mathrm{~K}$ for $2 \mathrm{~h}$ in a flowing dry $\mathrm{N}_{2}(30 \mathrm{~mL} / \mathrm{min})$. The reactant containing an aqueous solution of $20 \mathrm{wt} . \%$ glycerol in water was first evaporated in a preheater and then entered the reactor in down flow mode at a flow rate of $1 \mathrm{ml} / \mathrm{hr}$. The reaction products were condensed in a dry ice trap and collected hourly for analysis by GC equipped with ZB Wax capillary column and a flame ionization detector.

\section{RESULTS AND DISCUSSION}

\section{Catalyst Characterization}

Fig. (1A) shows the XRD patterns of WTZ, WAZ and WZ catalysts. In the XRD patterns of the WTZ catalyst, the characteristic peaks (\#) corresponding to crystalline $\mathrm{ZrTiO}_{4}$ [21] are observed. The XRD lines only due to tetragonal zirconia phase are observed in the case of WAZ catalyst, while both tetragonal and monoclinic zirconia phases were observed in the case of WZ catalyst [19, 20]. Fig. (1B) shows the XRD patterns of STZ, SAZ and SZ catalysts. The STZ catalyst shows characteristic peaks corresponding to $\mathrm{ZrTiO}_{4}(\#)$ and $\mathrm{Ti}_{2}\left(\mathrm{SO}_{4}\right)_{3}(\bullet)$ [21]. In the case of $\mathrm{SAZ}$ catalyst only tetragonal zirconia phase is observed [20], while a combination of tetragonal and monoclinic zirconia phases are observed in the case of SZ catalyst [19]. From both Fig. $(\mathbf{1 A}, \mathbf{B})$ it can be noted that there are no peaks due to the corresponding supports, alumina and titania. This observation suggests that alumina and titania are homogeneously mixed with the zirconia and are acting as structural stabilizers for zirconia [20,21].

Table 1 shows the BET surface area and ammonia-TPD results of various samples. It can be noted from this table that the specific surface area of SZ and STZ catalysts was higher than WZ and WTZ catalysts, however the specific surface area of SAZ catalyst was less than WAZ catalyst (SZ $>\mathrm{WZ}, \mathrm{STZ}>\mathrm{WTZ}$ and SAZ $<\mathrm{WAZ}$ ). This may be due to the formation of nonporous sulfates of $\mathrm{Al}$ and $\mathrm{Zr}$ in the SAZ catalyst. The less specific surface area of WZ and WTZ catalysts may be due to the penetration of the $\mathrm{W}$-oxide into the zirconia pores [19]. It can be observed from the ammonia-TPD results that all the samples show two types of acid sites in two different regions $[19,20,22]$. The $\mathrm{SO}_{4}{ }^{2-}$ promoted catalysts exhibit more number of strong acidic sites, less number of moderate and weak acidic sites when compared to that of $\mathrm{WO}_{\mathrm{x}}$ promoted catalysts [23]. The total amount of ammonia desorbed in the case of SAZ and STZ catalysts was found to be less than that of WAZ and WTZ catalysts. Where as in the case of SZ and WZ catalysts, the amount of ammonia desorbed was higher for the SZ catalyst than the WZ. 

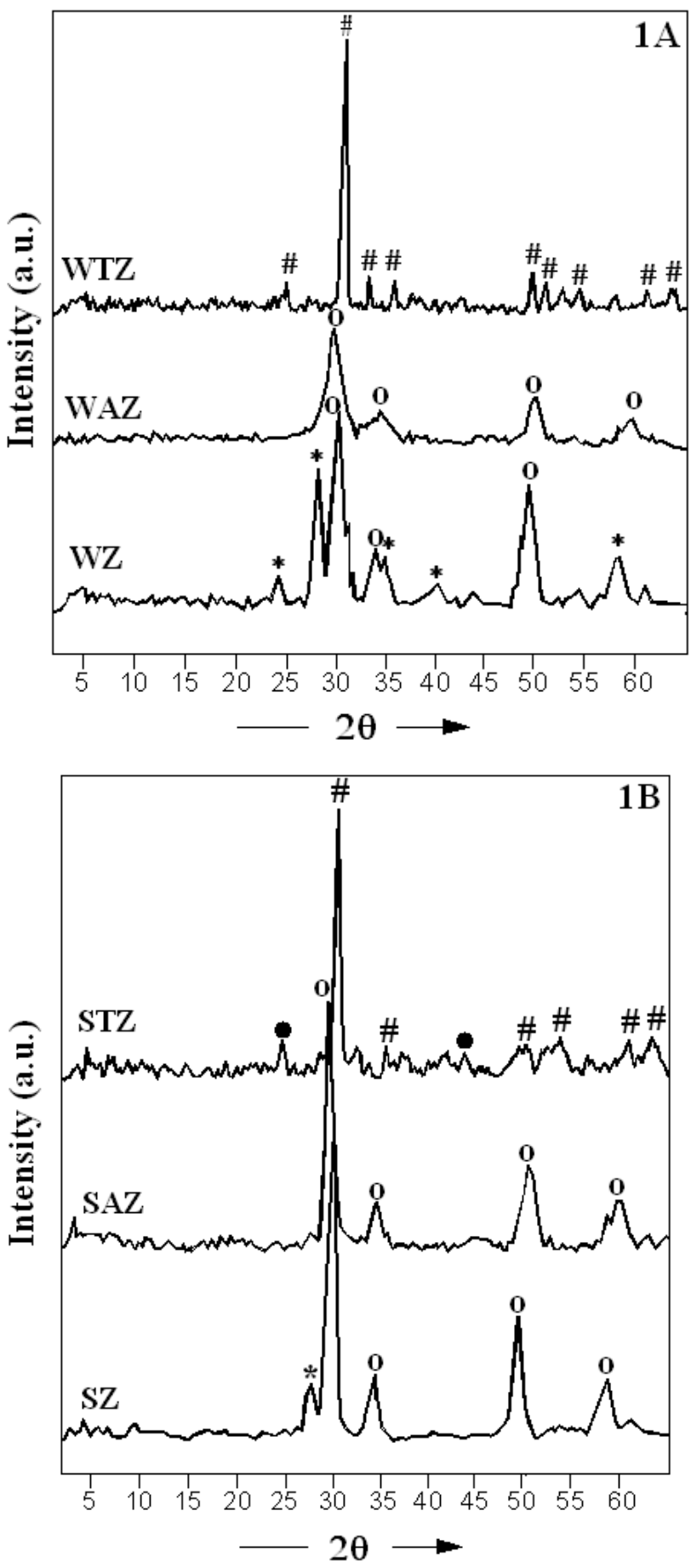

Fig. (1). X-ray powder diffraction patterns of (1A) WZ, WTZ and WAZ, and (1B) SZ, STZ and SAZ catalysts. (\#) $\mathrm{ZrTiO}_{4}$; (O) tetragonal $\mathrm{ZrO}_{2} ;(*)$ monoclinic $\mathrm{ZrO}_{2 .}(\bullet) \mathrm{Ti}_{2}\left(\mathrm{SO}_{4}\right)_{3}$.

Fig. (2A) shows the $\mathrm{Zr} 3 \mathrm{~d}$ photoelectron peaks of tungsten-oxide promoted catalysts. It can be observed that the $\mathrm{Zr} \mathrm{3d}$ lines are reasonably well resolved with good intensity. The XPS peaks at 182.9 and $185.2 \mathrm{eV}$ are corresponding to $\mathrm{Zr} 3 \mathrm{~d}_{5 / 2}$ and $\mathrm{Zr} 3 \mathrm{~d}_{3 / 2}$, respectively [24]. It is observed that a slight shift towards higher binding energy is noted in the case of WTZ catalyst when compared to that of $\mathrm{WAZ}$ and WZ catalysts. This is mainly due to the formation
Table 1. BET Surface Area, Total Acidity and $\mathrm{Zr}$ Electron Binding Energies (eV) of Various Promoted Zirconia Catalysts

\begin{tabular}{|c|c|c|c|c|c|}
\hline \multirow{2}{*}{ S. No. } & \multirow{2}{*}{ Catalyst } & \multirow{2}{*}{$\begin{array}{c}\text { BET } \\
\text { Surface }\end{array}$} & \multirow{2}{*}{$\begin{array}{c}\text { Total NH } \\
\text { Desorbed } \\
\left(\mathbf{m}^{2} / \mathbf{g}\right)\end{array}$} & \multicolumn{2}{|c|}{ Binding Energies (eV) } \\
\cline { 5 - 6 } & & $\mathbf{m m o l} / \mathbf{g})$ & $\mathbf{Z r ~ 3 d}_{\mathbf{5} / \mathbf{2}}$ & $\mathbf{Z r ~ 3 d}_{\mathbf{3} / 2}$ \\
\hline \hline 1 & WZ & 64 & 0.39 & 182.9 & 185.2 \\
\hline 2 & WTZ & 14 & 0.71 & 183.1 & 185.4 \\
\hline 3 & WAZ & 114 & 0.83 & 182.9 & 185.2 \\
\hline 4 & SZ & 100 & 0.69 & 182.9 & 185.2 \\
\hline 5 & STZ & 28 & 0.64 & 183.1 & 185.5 \\
\hline 6 & SAZ & 33 & 0.65 & 183.0 & 185.3 \\
\hline
\end{tabular}

of $\mathrm{ZrTiO}_{4}$ compound in the case of WTZ catalyst as observed from XRD results. Fig. (2B) shows the $\mathrm{Zr} \mathrm{3d}$ photoelectron peaks of $\mathrm{SO}_{4}{ }^{2-}$ promoted catalysts. It can be observed that the XPS peaks at 183.0 and $185.3 \mathrm{eV}$ are

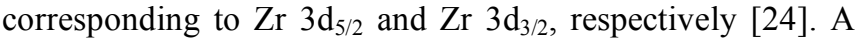
slight shift towards higher binding energy is observed in the case of STZ catalyst, which is mainly due to the formation of $\mathrm{ZrTiO}_{4}$ compound as noted from XRD analysis. However, a slight broadening and decrease in the intensity of the lines is noted in the case of SAZ catalyst. Interestingly, a slight shift towards higher binding energy and a significant broadening is noted in the case of $\mathrm{SO}_{4}{ }^{2-}$ promoted catalyst. These results reveal that the sulfate ion has exhibited a strong influence on the intensity and binding energy of the $\mathrm{Zr} 3 \mathrm{~d}$ lines.

\section{Catalytic Experiments}

The gas phase conversion of glycerol reaction is shown in Scheme 1. The possible major products in this reaction are acetol and acrolein. Acetol can be produced by the mono dehydration of glycerol, where as acrolein is produced by double dehydration of glycerol. Fig. (3) shows the glycerol conversion and the selectivity towards acrolein and acetol over promoted zirconia catalysts at $588 \mathrm{~K}$ during $3 \mathrm{~h}$ of catalytic run. It was noted that all catalysts exhibit excellent catalytic activity. The glycerol conversion and selectivity towards acetol in the case of $\mathrm{WO}_{\mathrm{x}}$ promoted catalysts is higher than that of the $\mathrm{SO}_{4}{ }^{2-}$ promoted catalysts. This may be due to the formation of strong acidic sites in the case of $\mathrm{SO}_{4}{ }^{2-}$ promoted catalysts which are prone to fast deactivation. But the selectivity towards acrolein is slightly higher in the case of $\mathrm{SO}_{4}{ }^{2-}$ promoted catalysts, because these catalysts possessed large number of strong acidic sites as confirmed from the ammonia-TPD results which favour increase in the selectivity of acrolein [25]. Among all catalysts, the WAZ catalyst exhibited the highest glycerol conversion of $\sim 99 \%$ and the selectivity towards acetol of $\sim 74 \%$.

Fig. (4) shows the time-on-stream activity studies over various catalysts at a reaction temperature of $588 \mathrm{~K}$. The $\mathrm{WO}_{\mathrm{x}}$ promoted catalysts exhibited better activity than the $\mathrm{SO}_{4}{ }^{2-}$ promoted catalysts. It is interesting to note that initially the glycerol conversion was high over all catalysts. However, the glycerol conversion was observed to decrease 

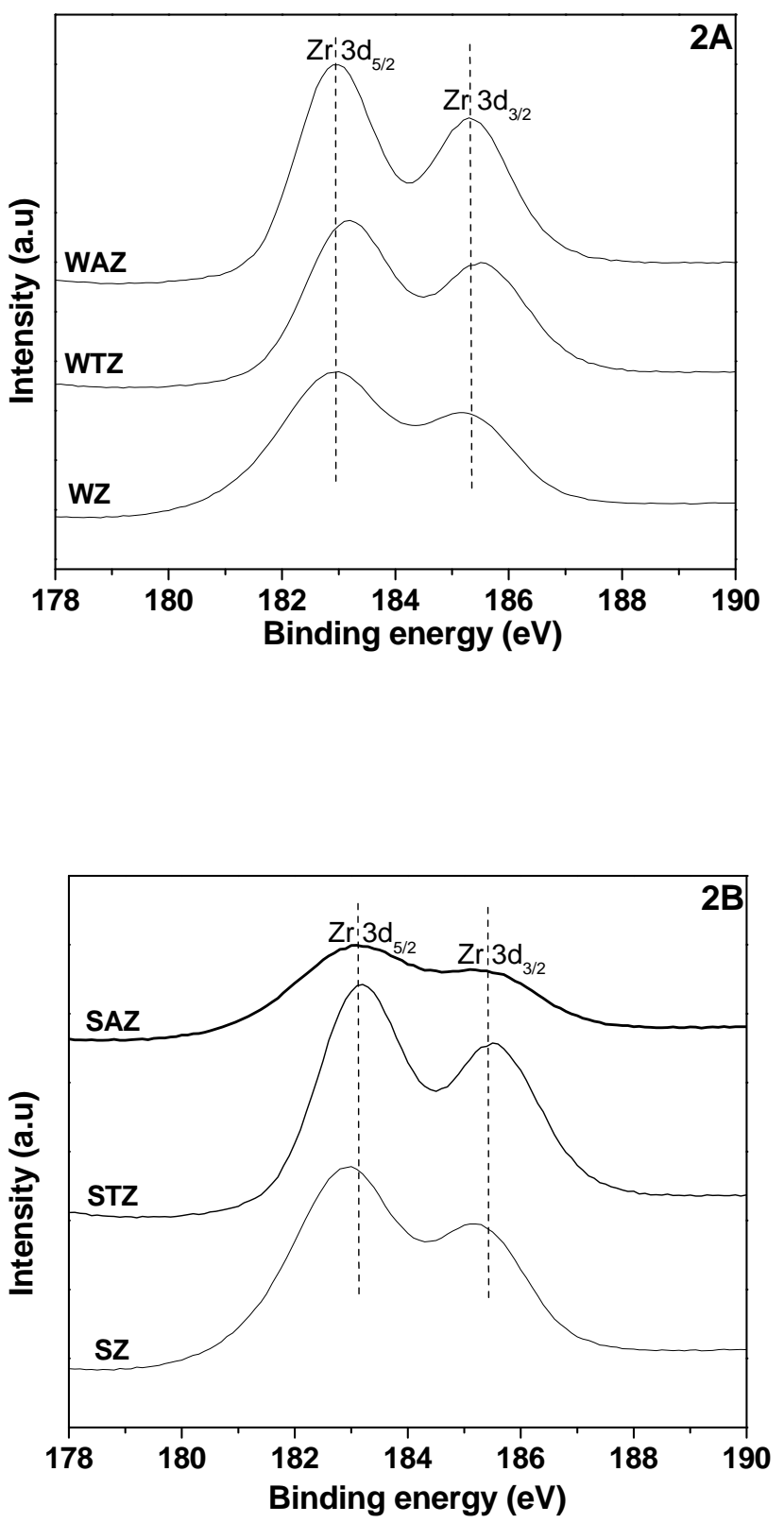

Fig. (2). The Zr 3d XPS spectra of (2A) WZ, WTZ andd WAZ, and (2B) SZ, STZ and SAZ catalysts.

with time in the case of $\mathrm{SO}_{4}{ }^{2-}$ promoted catalysts, while in the case of $\mathrm{WO}_{\mathrm{x}}$ promoted catalysts a slight decrease is noted. This is probably due to deactivation of $\mathrm{SO}_{4}{ }^{2-}$ promoted catalysts. Reason for the deactivation of $\mathrm{SO}_{4}{ }^{2-}$ promoted catalysts could be due to catalyst coking and/or formation of sulfuric acid at the reaction temperature (since reactant contains water), which lead to downstream contamination also [26]. Fig. (5) shows the results of timeon-stream selectivity of acetol over various catalysts at 588 $\mathrm{K}$ for $6 \mathrm{~h}$. The selectivity of acetol increased with the reaction time up to $3 \mathrm{~h}$ reaction. After $3 \mathrm{~h}$ of reaction the selectivity is slightly decreased. Among all catalysts, the WAZ catalyst showed high selectivity and decreased in the order of $\mathrm{WAZ}>\mathrm{WZ}>\mathrm{WTZ}>\mathrm{SZ}>\mathrm{SAZ}>\mathrm{STZ}$. These results reveal that the $\mathrm{WO}_{\mathrm{x}}$ promoted catalysts exhibit high selectivity towards acetol probably due to optimum acidity.
The large amount of strong acidic sites on the catalyst surface facilitate acrolein product through the formation of an intermediate, 3-hydroxypropanal, which is unstable at reaction conditions $[25,27]$. Thus, for higher selectivity of acetol moderate strength acidic sites are required.

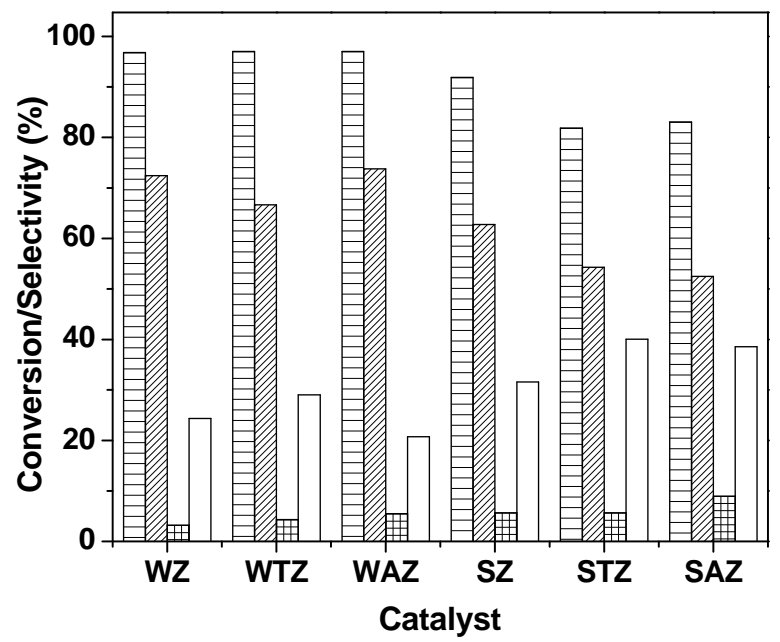

Fig. (3). Gas-phase conversion of glycerol to acetol over WZ, WTZ, WAZ, SZ, STZ and SAZ catalysts. Reaction conditions: catalyst amount $=0.5 \mathrm{~g}$; reaction temperature $=588 \mathrm{~K}$; reaction time $=3$ h. (目) glycerol conversion; $(\mathbb{Z})$ selectivity to acetol; (曲) selectivity to acrolein; ( $\square$ ) other byproducts ${ }^{\#}$. \# acetaldehyde, acetic acid, acetone, propanal, ethanol, methanol, and some unidentified products.

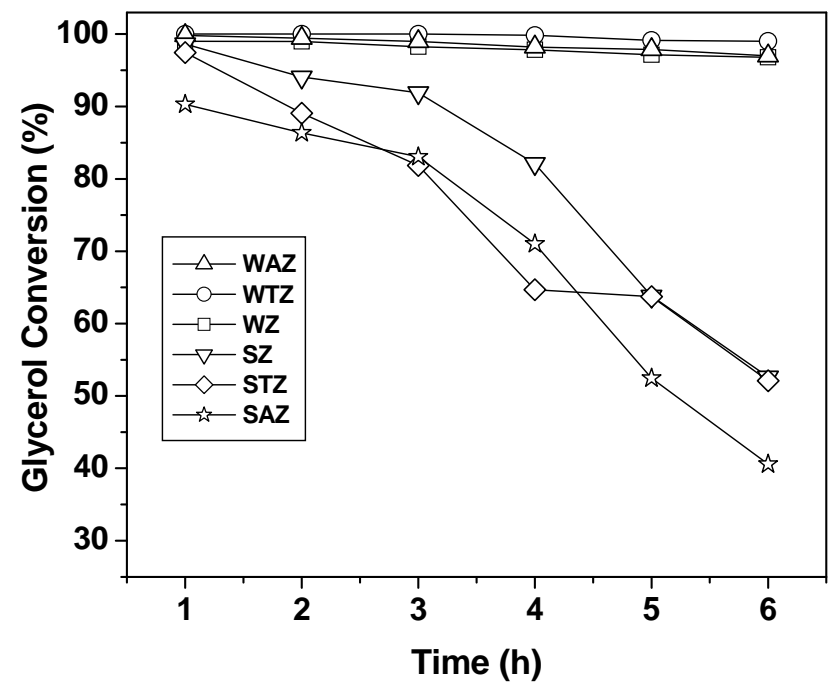

Fig. (4). The conversion of glycerol over WZ, WTZ, WAZ, SZ, STZ and SAZ catalysts is shown as a function of time-on-stream. Reaction conditions: catalyst amount $=0.5 \mathrm{~g}$; reaction temperature $=588 \mathrm{~K}$.

\section{CONCLUSION}

$\mathrm{SO}_{4}{ }^{2-}$ and $\mathrm{WO}_{\mathrm{x}}$ promoted $\mathrm{ZrO}_{2}$ and $\mathrm{M}-\mathrm{ZrO}_{2}\left(\mathrm{M}=\mathrm{Al}_{2} \mathrm{O}_{3}\right.$ or $\mathrm{TiO}_{2}$ ) solid acid catalysts were successfully prepared by coprecipitation and impregnation methods for vapour phase conversion of glycerol to acetol. It was found that the $\mathrm{SO}_{4}{ }^{2-}$ promoter strongly influences the physicochemical properties 


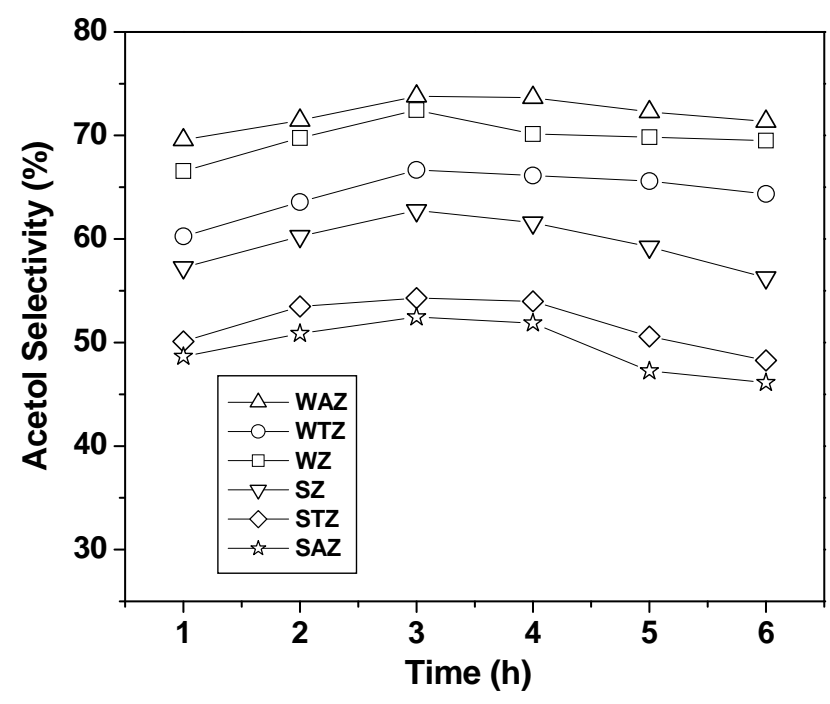

Fig. (5). Acetol selectivity over WZ, WTZ, WAZ, SZ, STZ and SAZ catalysts is shown as a function of time-on-stream. Reaction conditions: catalyst amount $=0.5 \mathrm{~g}$; reaction temperature $=588 \mathrm{~K}$.

of the support oxides. Among various catalysts investigated, the WAZ catalyst exhibited high surface area and more $\mathrm{NH}_{3}$ desorbed amount $(\mathrm{mmol} / \mathrm{g})$. The WAZ catalyst showed stable catalytic activity with highest glycerol conversion and selectivity of acetol. The $\mathrm{SO}_{4}{ }^{2-}$ promoted catalysts were readily deactivated when compared to $\mathrm{WO}_{\mathrm{x}}$ promoted catalysts.

\section{ACKNOWLEDGMENTS}

G.R. and P.S.R. thank Council of Scientific and Industrial Research, New Delhi, for the award of Senior Research Fellowships.

\section{REFERENCES}

[1] Huber, G.W.; Iborra, S.; Corma, A. Synthesis of transportation fuels from biomass: Chemistry, catalysts, and engineering. Chem. Rev. 2006, 106, 4044-4098.

[2] Chiu, C.W.; Dasari, M.A.; Sutterlin, W.R.; Suppes, G.J. Removal of residual catalyst from simulated biodiesel's crude glycerol for glycerol hydrogenolysis to propylene glycol. Ind. Eng. Chem. Res., 2006, 45, 791-795.

[3] Furikado, I.; Miyazawa, T.; Koso, S.; Shimao, A.; Kunimori, K.; Tomishige, K. Catalytic performance of $\mathrm{Rh} / \mathrm{SiO}_{2}$ in glycerol reaction under hydrogen. Green. Chem., 2007, 9, 582-588.

[4] Feng, J.; Fu, H.; Wang, J.; Li, R.; Chen, H.; Li, X. Hydrogenolysis of glycerol to glycols over ruthenium catalysts: Effect of support and catalyst reduction temperature. Catal. Commun., 2008, 9, 1458-1464.

[5] Brandner, A.; Lehnert, K.; Bienholz, A.; Lucas, M.; Claus, P. Production of biomass- chemicals and energy: Chemocatalytic conversions of glycerol. Top. Catal., 2009, 52, 278-287.

[6] Ott, L.; Bicker, M.; Vogel, H. Catalytic dehydration of glycerol in sub- and supercritical water: a new chemical process for acrolein production. Green Chem., 2006, 8, 214-220.
[7] Wolfson, A.; Dlugy, C.; Shotland, Y. Glycerol as a green solvent for high product yields and selectivities. Environ. Chem. Lett., 2007, 5, 67-71.

[8] Wolfson, A.; Dlugy, C. Glycerol as an alternative green medium for carbonyl compound reductions. Org. Commun., 2009, 2, 34-41.

[9] Katryniok, B.; Paul, S.; Capron, M.; Dumeignil, F. Towards the sustainable production of acrolein by glycerol dehydration. Chem. Sus. Chem., 2009, 2, 719-730.

[10] Dasari, M.A.; Kiatsimkul, P.P.; Sutterlin, W.R.; Suppes, G.J. Lowpressure hydrogenolysis of glycerol to propylene glycol. Appl. Catal. A Gen., 2005, 281, 225-231.

[11] Chaminand, J.; Djakovitch, L.; Gallezot, P.; Marion, P.; Pinel, C.; Rosier, C. Glycerol hydrogenolysis on heterogeneous catalysts. Green Chem., 2004, 6, 359-361.

[12] Garcia, R.; Besson, M.; Gallezot, P. Chemoselective catalytic oxidation of glycerol with air on platinum metals. Appl. Catal. A Gen, 1995, 127, 165-176.

[13] Carrettin, S.; McMorn, P.; Johnston, P.; Griffin K, Hutchings, J.G Selective oxidation of glycerol to glyceric acid using a gold catalyst in aqueous sodium hydroxide. Chem. Commun., 2002, 7, 696-697.

Huang, L.; Zhu, Y.L.; Zheng, H.Y.; Li, Y.W.; Zeng, Z.Y. Continuous production of 1,2-propanediol by the selective hydrogenolysis of solvent-free glycerol under mild conditions. $J$. Chem. Tech. Biotec., 2008, 83, 1670-1675.

[15] Mane, R.B.; Hengne, A.M.; Ghalwadkar, A.A.; Vijayanand, S.; Mohite, P.H.; Potdar, H.S.; Rode, C.V. Cu:Al Nano catalyst for selective hydrogenolysis of glycerol to 1,2- propanediol. Catal. Lett., 2010, 135, 141-147.

[16] Chiu, C.W.; Dasari, M.A.; Suppes, G.J.; Suttterlin, W.R. Dehydration of glycerol to acetol via catalytic reactive distillation. AIChE J., 2006, 52, 3543-3548.

[17] Yamaguchi, A.; Hiyoshi, N.; Sato, O.; Rade, C.V.; Shirai, M. Enhancement of glycerol conversion to acetol in high-temperature liquid water by high-pressure carbon dioxide. Chem. Lett., $\mathbf{2 0 0 8 ,}$ 37, 926-927.

[18] Chiu, C.W.; Tekeei, A.; Sutterlin, W.R.; Ronco, J.M.; Suppes, G.J. Low-pressure packed-bed gas phase conversion of glycerol to acetol. AIChE J., 2008, 54, 2456-2463.

[19] Reddy, B.M.; Sreekanth, P.M.; Reddy, V.R. Modified zirconia solid acid catalysts for organic synthesis and transformations. $J$. Mol. Catal. A Chem., 2005, 225, 71-78.

[20] Reddy, B.M.; Sreekantha, P.M.; Yamadab, Y.; Kobayashib, T. Surface characterization and catalytic activity of sulfate-, molybdate- and tungstate-promoted $\mathrm{Al}_{2} \mathrm{O}_{3}-\mathrm{ZrO}_{2}$ solid acid catalysts. J. Mol. Catal. A Chem., 2005, 227, 81-89.

[21] Reddy, B.M.; Sreekantha, P.M.; Yamadab, Y.; Xu, Q.; Kobayashi, T. Surface characterization of sulfate, molybdate, and tungstate promoted $\mathrm{TiO}_{2}-\mathrm{ZrO}_{2}$ solid acid catalysts by XPS and other techniques. Appl. Catal. A Gen., 2002, 228, 269-278.

[22] Reddy, B.M.; Khan, A. Recent advances on $\mathrm{TiO}_{2}-\mathrm{ZrO}_{2}$ mixed oxides as catalysts and catalyst supports. Catal. Rev., 2005, 47, 257-296.

[23] Corma, A.; Fornes, V.; Juan-Rajadell, M.I.; Lopez-Nieto, J.M. Influence of preparation conditions on the structure and catalytic properties of $\mathrm{SO}_{4}{ }^{2-} / \mathrm{ZrO}_{2}$ superacid catalysts. Appl. Catal. A. Gen., 1994, 116, 151-163.

[24] Wagner, C.D.; Riggs, W.M.; Davis, L.E.; Moulder, J.F. Handbook of X-ray photoelectron spectroscopy, perkin-elmer co., $M N, 1978$.

[25] Ulgen, A.; Hoelderch, W. Conversion of glycerol to acrolein in the presence of $\mathrm{WO}_{3} / \mathrm{ZrO}_{2}$ catalysts. Catal. Lett., 2009, 131, 122-128.

[26] Reddy, B.M.; Patil, M.K. Promoted zirconia solid acid catalysts for organic synthesis. Cur. Org. Chem., 2008, 12, 118-140.

[27] Kinage, A.K.; Upare, P.P.; Kasinathan, P.; Hwang, Y.K.; Chang, J.S. Selective conversion of glycerol to acetol over sodium-doped metal oxide catalysts Catal. Commun., 2010, 11, 620-623.

This is an open access article licensed under the terms of the Creative Commons Attribution Non-Commercial License (http://creativecommons.org/licenses/by-nc/ 3.0/) which permits unrestricted, non-commercial use, distribution and reproduction in any medium, provided the work is properly cited. 